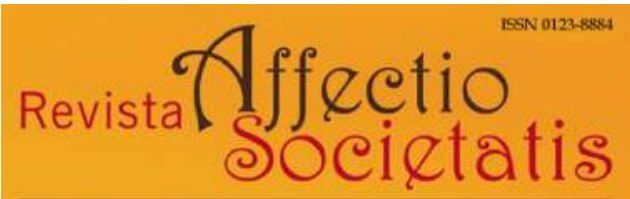

Departamento de Psicoanálisis | Universidad de Antioquia

Revista Affectio Societatis

Departamento de Psicoanálisis

Universidad de Antioquia

revistaaffectiosocietatis@udea.edu.co

ISSN (versión electrónica): 0123-8884

Colombia

Revista Affectio Societatis, Vol. 16, N. ${ }^{\circ}$ 30, enero-junio de 2019

Art. \# 10 (pp. 185-207)

Departamento de Psicoanálisis, Universidad de Antioquia Medellín, Colombia 


\title{
BRUJERÍA E HISTERIA: EL SÍNTOMA COMO CRÍTICA ${ }^{1}$
}

\author{
Rigoberto Hernández Delgado² \\ Universidad Michoacana de San \\ Nicolás de Hidalgo, México \\ natusetmortem@gmail.com \\ ORCID: 0000-0002-0542-4975
}

DOI: 10.17533/udea.affs.v16n30a10

\section{Resumen}

Esta comunicación pretende mostrar cómo la histeria y otros fenómenos corporales históricamente conocidos (brujería y posesión demoniaca) pueden ser leídos como expresiones de un modo discursivo más allá de una mera interpretación clínica, sin decir que dicha interpretación no sea no sea posible y legítima de cierta manera. El discurso de la histeria sería aquello que se expresa desde afuera o desde adentro, pero siempre contra el con-

junto de discursos dominantes en una época y en un contexto posibles y legítimos de cierta manera. El discurso de la histeria sería aquello que se expresa en lo social de modo concreto, es decir, una forma de discurso subversivo y crítico cuyo rasgo transversal ha sido el de usar al cuerpo como modalidad privilegiada de expresión.

Palabras clave: histeria, discurso histérico, síntoma, poder, psicoanálisis.

1 Una versión recortada y sintetizada de este artículo fue publicada en el número 9 de la revista Teoría y crítica de la psicología, con el título "Sociedad e histeria: el síntoma como crítica y subversión". Disponible en: http://teocripsi.com/ojs/ index.php/TCP/article/view/201/182.

2 Licenciado en Psicología por la Universidad Michoacana de San Nicolás de Hidalgo. Mtro. en Psicología Clínica por la Universidad Autónoma de Querétaro. Miembro del Comite Editoral de la revista "Teoría y Critica de la Psicología" desde 2013. Autor de varios artículos y capítulos de libros sobre psicoanálisis, filosofía y estudios sociales. 


\section{WITCHCRAFT AND HYSTERIA: THE SYMPTOM AS CRITIC}

\section{Abstract}

This paper aims at showing how hysteria and other historically known corporal phenomena (witchcraft and demonic possession) can be read as expressions of a form of discourse instead of a mere clinic interpretation, not saying that such an interpretation is not possible and legitimate in some way. Hysteria discourse would express from the outside or from the inside, but always against the discourses dominant in a time and context that were possible and legitimate in some way. Hysteria discourse would express in the social in a concrete way, i.e., as a form of subversive and critical discourse whose transverse feature has been the use of the body as the privileged way of expression.

Keywords: hysteria, hysterical discourse, symptom, power, psychoanalysis.

\section{SORCELLERIE ET HYSTÉRIE : LE SYMPTÔME COMME CRITIQUE}

\section{Résumé}

Cet article vise à démontrer que l'hystérie et d'autres phénomènes corporels historiquement connus (sorcellerie et possession démoniaque) peuvent être interprétés en tant qu'expressions d'un mode discursif, au-delà d'une simple interprétation clinique, ce qui ne veut pas dire pour autant que celle-ci ne soit pas possible et légitime d'une certaine manière. Le discours de l'hystérie serait ce qui est exprimé de l'intérieur ou de l'extérieur, mais toujours à l'encontre de l'ensemble de discours dominants dans une époque et dans un contexte donnés. Le discours de l'hystérie serait ce qui est exprimé dans le domaine social de manière concrète, c'est-à-dire, il s'agit d'une forme de discours subversif et critique dont le trait transversal a été celui de l'utilisation du corps en tant que modalité privilégiée d'expression.

Mots-clés : hystérie, discours hystérique, symptôme, pouvoir, psychanalyse.

Recibido:04/02/2018 • Aprobado:12/07/2018 
Es para nosotros bien sabido que la categoría psicopatológica de la "histeria", tan cara a Freud en su tiempo, se ha esfumado de los grandes manuales internacionales de clasificación de enfermedades o de trastornos mentales que norman actualmente la práctica clínica "psi". Incluso, también dicha categoría se ha ido difuminando en el contexto del psicoanálisis oficial desde la segunda mitad del siglo $\mathrm{XX}, \mathrm{y}$ ha sido sustituida, al igual que en los manuales psiquiátricos, por otras categorías que ponderan metonímica o metafóricamente algún aspecto sintomático de ella, por ejemplo, por las categorías de "trastorno narcisista" o "personalidad borderline" (Maleval, 1994). Todo está dado en nuestro tiempo para que la potencia explicativa y terapéutica del concepto psicoanalítico de "histeria" se pierda, se niegue, se denoste, y para que los síntomas, los enfermos -su correlato empíricovuelvan a ser tachados como meros simuladores, o bien para disolver el cuadro en otras áreas médicas que no pueden o no quieren decir nada al respecto. Un ejemplo de esto en nuestros días es el problema de la llamada "fibromialgia", cuya característica principal es el dolor crónico, problema del cuál la Organización Mundial de la Salud reconoce su presencia en un porcentaje de entre el tres y seis por ciento de la población mundial (Nucamendi, Guillén y Sánchez, 2013). De este porcentaje se sabe que entre el ochenta y el noventa por ciento de los casos corresponde a una población de mujeres (Ibíd). En nuestro país, sin embargo, no contamos con estadísticas respecto de su incidencia pues su existencia no es avalada por los organismos de salud pública, ni mucho menos reconocida como una enfermedad discapacitante.

No me gustaría solamente insistir en la necesidad de reconocer la existencia de lo que llamamos "histeria", sino más bien en mostrar que sus manifestaciones sintomáticas persisten, como hace más de un siglo, apuntando al límite mismo de la comprensión médica, psiquiátrica o psicológica; y, en ese mismo sentido, lo que me gustaría mostrar a continuación es cómo la histeria y otros fenómenos corporales históricamente conocidos pueden ser leídos como expresiones de un modo discursivo que va más allá de una mera interpretación clínica, sin decir que dicha interpretación no sea posible y legítima de cierta manera. El discurso de la histeria sería aquello que se expresa desde afuera o desde adentro, pero siempre contra el conjunto de discursos dominantes, contra unas normas científicas o morales, contra 
un sistema político o económico vigente, contra un sistema cultural de diferenciación sexual presente en una época y en un contexto social concretos. La histeria sería una forma de discurso subversivo y crítico, cuyo rasgo transversal ha sido el de poner en juego al cuerpo como modalidad privilegiada de expresión.

Así por ejemplo, las manifestaciones extendidas de brujería en la Europa de los siglo XVI y XVII podrían ser comprendidas como formas discursivas críticas contra un poder que se afirmaba contundentemente en ese momento a través de los mecanismos de la evangelización cristiano católica y de los movimiento de reforma protestante, mientras que los síntomas histéricos podrían ser puestos en relación, como desafío y puesta en interdicción, con el discurso y la técnica médicos dominantes en el contexto del paradigma de la anatomo-clínica patológica imperante en la Europa decimonónica.

Sostengo que esta perspectiva puede encontrarse, como punto de acuerdo, aunque mediante formulaciones distintas, tanto en los análisis históricos que el filósofo francés Michel Foucault elabora en varios momentos de su obra, como también en los trabajos de otros historiadores y filósofos como Gladis Swain, Marcel Gauchet, Henry Ellenberger, Georges Didi-Huberman, Paul Bercherie y otros; esta perspectiva se encuentra también en la enseñanza del psicoanalista francés Jacques Lacan, sobre todo desde finales de los años sesenta, sin decir que no estuviera ya en germen en la obra de Freud, aunque sin una formulación tan explícita.

Comenzaré por indagar los fenómenos asociados a la brujería y a la posesión demoniaca desde el final de la Edad Media, de acuerdo a la perspectiva de algunos de los autores mencionados, luego abordaremos el problema de la histeria desde la Antigüedad, pero enfocándonos particularmente en el periodo en el cual su estudio es tomado por la neurología de la segunda mitad del siglo XIX; finalmente procederemos a relacionar lo anterior con la propuesta lacaniana del llamado "discurso histérico" y avanzaremos a concluir mediante un análisis a partir de las herramientas conceptuales del marxismo lacaniano. 


\section{La brujería y la posesión demoniaca como reacción al avance del poder religioso}

La cantidad de escritos que podemos encontrar actualmente en torno al tema de la brujería es enorme y por lo tanto muy difícil de abarcar. Si nos enfocamos únicamente en aquella bibliografía que atiende el problema en su desarrollo histórico, la dificultad aún persiste. Sabemos que la figura de la bruja estaba ya contemplada en la literatura de la Grecia antigua, desde hace al menos 2500 años. En obras tales como El asno de oro de Apuleyo o el Satiricón de Petronio, ya podemos encontrar descripciones de mujeres a las que se les atribuyen poderes sobrenaturales o conocimientos para elaborar potajes y preparados que pueden trastocar el pensamiento, los deseos, la forma física de los hombres, o incluso modificar las leyes de la naturaleza oponiéndose a los dioses mismos. No deja de percibirse la advertencia explícita o implícita que acompaña a las historias plasmadas en esas obras, advertencia sobre el carácter peligroso de la bruja y, de manera más general, sobre el carácter peligroso de la mujer. La tradición de las hechiceras divinas le da forma a ciertos cultos antiguos que serán el modelo previo y precristiano de la bruja occidental de finales de la Edad Media. Entre esas hechiceras divinas encontramos a la infernal Hécate con sus tres rostros, la seductora Cirse que cautivó a Ulises, la astuta y vindicativa Medea, entre otras (Pedraza, 2014).

Pero nos interesa sobre todo destacar aquel modelo de bruja y de brujería que es mucho más reciente y ha pasado por el filtro de una interpretación cristiana correspondiente a la última etapa de la Edad Media, justo en el tiempo en el cual se escriben los primeros documentos que expresan un mandato por parte de las instituciones cristianas a perseguir y acabar con la brujería y con toda forma de paganismo y herejía. En particular, el siglo XIV de nuestra era marca el punto en el cual una nueva conexión entre la brujería y la demonología se pone en marcha; las primeras descripciones de aquelarres datan precisamente de ese tiempo y coinciden justamente con una serie de fenómenos sociales, políticos y naturales que marcarán el pasaje de la Edad Media hacia el Renacimiento y la Modernidad. 
En 1486 se publica el famoso Malleus Maleficarum, el Martillo de las Brujas, escrito en Alemania por dos inquisidores dominicos: los teólogos Jacob Sprenger y Heinrich Kramer. Este texto contiene una descripción pormenorizada -absolutamente cargada de misoginiade las características de las brujas, de sus ritos, reuniones, así como de los castigos y penas aplicables a esos delitos. Los procesos inquisitoriales por brujería se extendieron por la mayoría de los países europeos entre los siglos XVI y XIX; independientemente de las disputas entre católicos y protestantes, ambos bandos del cristianismo adoptaron para sí la misión de exterminar el riesgo de brujería. El historiador Jean Delumeau (2012/1978) afirma que las cifras de las víctimas mortales derivadas de los procesos de brujería en ese tiempo son en realidad incalculables de forma exacta, pero se cuentan por decenas o cientos de miles. En particular, es necesario hacer notar que la persecución de brujas durante los albores de la modernidad occidental denota también una estigmatización de la mujer como un ser marcado por la maldad infernal.

Michel Foucault (2006/1974) nos muestra, en su curso del Colegio de Francia titulado Los anormales, que los fenómenos de brujería en esa época están intrínsecamente relacionados con un conjunto de estrategias políticas puestas en marcha por las instituciones cristianas, católicas y protestantes, como respuesta ante la puesta en cuestionamiento de sus propios fundamentos, su legitimidad y su predominancia social. Para Foucault, los fenómenos de brujería, pero también los de posesión demoniaca y de misticismo, no serían sino el efecto antagónico de una oleada de cristianización que se produce desde el siglo $\mathrm{XV}$ en el Occidente europeo. Sobre todo, por ejemplo, el cuerpo convulsivo de las místicas y las posesas, aunque también las formas de la brujería femenina, serían el efecto retardado de los nuevos mecanismos confesionales que se instalaron en el Concilio de Trento y en los famosos Tratados de Carlos Borromeo a partir del siglo XVI. Efecto y cuestionamiento, al mismo tiempo, de una nueva política de vigilancia de los cuerpos que la matriz confesional instaló y que, de acuerdo a Foucault, sigue rigiendo la manera en que se delinea la individualidad moderna en la sociedad actual, no ya únicamente por medio del ritual confesional cristiano, sino por medio del imperativo amplio de hacer pasar la totalidad de nuestras vidas por el filtro de un 
discurso confesional que puede tomar la forma del examen médico, la psicoterapia, la evaluación pedagógica, etc.

Para Foucault (2006/1974), la brujería descrita en las actas de los procesos inquisitoriales se muestra como un fenómeno limítrofe, es decir, como una manifestación reactiva desde el límite mismo de los mecanismos de poder mencionados. Predominantemente, la brujería, la bruja, el aquelarre mismo, encuentran su lugar propio en la periferia no ya de las ciudades sino de las aldeas, en el campo, en el bosque, en el monte.

Por otro lado, la posesión mística o demoniaca se deslinda de la brujería por cuanto puede entenderse como "contrapoder", como manifestación de una resistencia que se erige en el interior mismo de dichos mecanismos: en la ciudad, y dentro de ella en los conventos, en los monasterios, al interior de las iglesias. Basta atender a la literatura de la época o a los escritores góticos del siglo XVIII y XIX para darse una idea de cómo es que el riesgo de la tentación demoniaca que producen los fenómenos corporales de posesión, se percibe en el mismo sitio en donde se profesa la fe cristina. Por ejemplo, en Los elixires del diablo de Hoffman, en El Monje de Lewis, en Melmoth el errabundo de Maturin, etc., la temática del monje cristiano que pacta con el demonio en la celda del monasterio es recurrente.

Podemos tomar un ejemplo paradigmático que muestra cómo es que las manifestaciones de los fenómenos corporales se encarnaban en, y dependían de, un conjunto de relaciones de saber y poder que se imponían directamente sobre el cuerpo de los afectados. En su profundo estudio sobre la llamada "posesión de Loudun", Michel de Certeau (2012/1970) describe y analiza los acontecimientos relativos a los procesos jurídicos, eclesiásticos y médicos, llevados a cabo en la comunidad de Loudun, en Francia, desde el año de 1632, a propósito de una serie de más de veinte casos de posesión demoniaca entre las monjas ursulinas del convento local que llevaron al enjuiciamiento y ejecución del sacerdote Urbin Grandier encontrado culpable de bujería.

El análisis realizado por De Certeau coincide con la propuesta de Foucault pues muestra cómo es que los signos de la posesión tienen una relación estrecha con los protocolos mediante los cuales los "exper- 
tos" (clérigos, teólogos, médicos) interrogaban y exigían la manifestación de dichos signos. De Certeau usa el término "teatro" para referirse a la escena en la cual las monjas, obedeciendo las órdenes de los inquisidores, perdían la conciencia para dar voz y expresión a un tropel de demonios que tomaban posesión de sus cuerpos. Tanto antes como durante los procesos de exorcismo se evidencia cómo es que el cuerpo de las posesas se hace valer como un campo de batalla; se transforma desde un cuerpo dócil que se inclina ante el crucifijo, a un cuerpo rebelde que escupe sobre el rostro del cura, que habla lenguas ininteligibles y que levita, según los testimonios, a varios metros sobre el suelo. Sobre estas escenas, muchas veces repetidas y consignadas en las actas, De Certeau (2012/1970) elabora dos conclusiones de importancia capital:

Entre veinte más, dos rasgos revelan en los exorcistas esta situación ambigua de la teología ante los hechos y ante sus observadores médicos: por una parte, la distorsión del exorcismo que, de acto litúrgico, de operación salvadora y reveladora, se convierte en un arma de combate teatral, la confesión de una pérdida a través del trabajo de una recuperación; por otra parte, después de haber invertido las posiciones tradicionales, la verdad debe buscarse en la mentira y es el mentiroso quien la dice (p. 159).

Podemos, entonces, destacar varios aspectos del fenómeno: primero, su carácter relacional que involucra a las posesas pero también a los expertos, así como a un público ávido de escenas excitantes, y por lo tanto, su relieve teatral en cuanto se ofrece a la mirada de otro; luego, su manifestación predominantemente corporal y su forma agonística, es decir, a la manera de un enfrentamiento, como una lucha de fuerzas que se oponen; y finalmente, el carácter ficcional de la verdad que muestra su revelación mediante el rodeo de la farsa exagerada al extremo mediante un despliegue teatral.

\section{La histeria contra la medicina primero y contra la neurología después: la desnaturalización de la enfermedad}

La histeria para nosotros es bastante conocida no solamente desde su reactivación como foco de atención médica en el siglo XIX, sino como 
una condición patológica de la mujer descrita desde hace miles de años. Ya Hipócrates, en el siglo VI a. C. describía en su "Tratado de las enfermedades de la mujer", las características de esta enfermedad atribuidas en su origen a la hipermovilidad e irritabilidad del útero en el interior del cuerpo de la mujer. Su síntoma más característico, aquel que la acercaba a la llamada "enfermedad sagrada" (la epilepsia), era el temblor incontrolable; pero también iba acompañada de un tropel de síntomas absolutamente heteróclitos entre sí: dolores en cualquier sitio del cuerpo, anestesias, parálisis, irritabilidad, labilidad emocional, ceguera, etc. Los peculiares medios terapéuticos recomendados por el propio Hipócrates muestran que los griegos asumían la histeria como inextricablemente relacionada con la sexualidad de la mujer, ya que puede entenderse que su sintomatología se debe a una falta de satisfacción de la función del órgano en cuestión, o sea la reproducción (Simon, 1984/1978).

Esta concepción de la histeria se enmarca en la cosmovisión griega, puesto que cristaliza un modelo social y político, al mismo tiempo que una concepción de la diferencia sexual aceptada en ese tiempo. En primer lugar, y como lo muestra Hanna Arendt (2010/1958), la polis griega dividía en su interior el espacio de la vida en las dimensiones contrapuestas de lo público y lo privado; lo público correspondiente al ámbito de la ciudanía, la política, el lenguaje y lo masculino, mientras que lo privado era identificado con el terreno de las relaciones familiares, el hogar, la producción económica y la reproducción biológica, así entonces, el sitio natural de la mujer.

Esta división de espacios, que traduce una división política de los cuerpos en función de sus caracteres sexuales, partía del supuesto, señalado por la historiadora Gladis Swain (1994), de que el cuerpo femenino prolongaba a la naturaleza y su función generatriz, a la manera en que se correspondían el macrocosmos con el microcosmos. De tal forma que la persona individual de la mujer se desposeía de su propio cuerpo en tanto que su capacidad reproductiva le pertenecía a la naturaleza. El útero era ese órgano mediante el cual la naturaleza se expresaba, en toda su potencia, en el cuerpo de la mujer. Esto llevó a Platón (2000/360 a.C.) a sugerir hace más de 2000 años, en su diálogo Timeo, que la mujer era una suerte de "animal deseoso de 
procrear" (p. 720). Debe entenderse que el alma, definida por antonomasia como alma racional por el filósofo de la Antigüedad, era una propiedad diferencial del hombre, quien se acercaba más al mundo divino de las ideas, mientras que la mujer, en su animalidad, era parte del escenario de la naturaleza.

La función sexual reproductiva era aquello que debía ser satisfecho en la mujer, no tanto porque su deseo individual estuviera al mando de esa necesidad, sino porque era la expresión de la capacidad generadora de la naturaleza misma; así, entonces, los síntomas histéricos eran el reclamo del cosmos interrumpido en su funcionamiento natural. Este modelo de ordenamiento del mundo, tanto de la naturaleza como de la ciudad, fundamenta, justifica y mitifica, con una evidente misoginia, la desigualdad entre hombres y mujeres en la cultura helénica antigua. La confiscación, regulación y control del cuerpo de la mujer por el poder depositado en las instituciones que mantenían el orden social en ese contexto, colocaba al hombre en una relación de evidente ventaja, pudiendo participar en la vida pública y en todos los aspectos de lo que podríamos denominar, siguiendo a Agamben (2006), la vida de acuerdo a la concepción antigua de bios, es decir, la vida como potencia de realización, la vida humana manifestada en sus formas política, ética, artística, filosófica, etc., mientras que reducía a la mujer a una vida en el mero sentido del zoe griego, como pura vida biológica.

Por ello en su famoso estudio sobre el cuerpo y el sexo, Thomas Laqueur (1994/1990) muestra que para los griegos los órganos reproductores de la mujer eran concebidos como un producto inacabado, como una forma imperfecta de los órganos reproductores del hombre, o incluso como el cuerpo del hombre vuelto al revés. Por todo esto, en el contexto de estas relaciones políticas de la antigüedad griega, el cuerpo de la mujer no dejaba de mostrar una serie de resistencias ante las sujeciones de las que era objeto; la histeria y sus síntomas tendían a poner en duda la cosmovisión griega, al mostrarse como un cuerpo femenino reacio a cumplir su propio fin, su telos. En un mundo helénico, en donde cada cosa tiene su lugar y su fin propios, la histeria representaba el rompimiento del orden natural, y el encargado de hacer retornar a ese cuerpo al eslabonamiento ordenado de las 
causas y los efectos era el médico. No solamente la histeria mostraba la inconformidad del cuerpo -que no de la consciencia necesariamente- de la mujer con el orden socio-político y económico en el que se subsumía en el mundo griego clásico, hemos de reconocer, de acuerdo al minucioso trabajo histórico de Sarah B. Pomeroy (1999/1987), que las válvulas de escape por las cuales se reconducía la rebelión corporal femenina hacia cauces relativamente seguros y socialmente aceptados eran múltiples, entre otros por ejemplo: los cultos religiosos a la diosa Atenea, los misterios de Demeter y Core en Eleusis y la celebración exclusivamente femenina de las Tesmoforias, también y por otro lado, mediante la prostitución.

La histeria fue, a lo largo de la historia de Occidente, desde la antigüedad hasta el alba de la modernidad, una de esas enfermedades que conformaban el amplio y difuso espectro de lo que Franklyn Rausky (1977), retomando una feliz expresión de J. L. Moreno, ha denominado el "proletariado terapéutico". Se refiere propiamente a aquellos enfermos afectados por toda clase de malestares, tanto físicos como anímicos, y que no encontraban en los tratamientos médicos una cura satisfactoria para sus síntomas. Enfermos que debían resignarse a permanecer cautivos de sus propios males en tanto que la medicina, o no ofrecía medios para su curación, o sencillamente terminaba por reconocerlos como falsos enfermos. Durante los siglos XVII y XVIII, las llamadas "enfermedades de los vapores", las "enfermedades de los nervios", las "enfermedades de la imaginación", las convulsiones, el "spleen", la propia histeria también, entre otras, representaron el límite de toda posible inteligibilidad por parte de la razón médica imperante en la cultura de la época (Rausky, 1977).

El desarrollo de la llamada "psiquiatría dinámica", aquella que se avocó a estos problemas, según nos lo describe el historiador Henry Ellenberger (1976/1970), llega a un punto culminante en la segunda mitad del siglo XIX, desde el momento en el cual al menos dos escuelas francesas de neurología tomaron a su cargo el problema de la histeria y emplearon para su estudio el método, hasta ese momento profundamente desacreditado, de la hipnosis. Por un lado, la escuela de Hypolitte Bernheim en la ciudad de Nancy en Francia, y por otro, la escuela de Jean Martín Charcot asentada en el hospital parisino de 
La Salpêtrière; de las dos, la que ha pasado sin duda a la posteridad con renombre y una influencia prominentes es la segunda, la del neurólogo Charcot.

A partir de la década de 1870, y debido a un cierto número de problemas prácticos relacionadas con la reorganización de un pabellón del hospital, a Charcot se le impuso la necesidad de establecer un criterio diferencial entre, por un lado, los cuadros de epilepsia reales, es decir, aquellos cuya etiología respondía a algún tipo de lesión orgánica, y, por otro lado, los cuadros de histeria epiléptica, es decir, los cuadros de falsas epilepsias que no derivaban de alguna causa orgánica. Para ello, con su alumno, el médico y dibujante Paul Richer, Charcot elabora en 1881 la descripción gráfica del llamado "gran ataque histérico" o "gran histeria" en todas sus fases: la epileptoide, la de los grandes movimientos o del clownismo, la de las actitudes pasionales y la del delirio (Charcot, 1981/1882). La descripción grafica mediante los bocetos de Richer y de un buen número de fotografías de las distintas posturas y actitudes histéricas fueron publicadas posteriormente en la revista titulada "Iconografía fotográfica de la Salpêtrière", en dos ediciones sucesivas (Didi-Huberman, 2007/1982).

Esa condición proteica, la histeria, que puede adoptar la forma de cualquier otra enfermedad, orgánica o anímica, había sido por fin caracterizada por Charcot en lo que tiene de más propio y en aquello que permite reconocerla como una entidad nosológica autónoma. Pero Charcot y su escuela se esforzaron no solamente por distinguir nosológicamente a la histeria, sino por autentificarla como una enfermedad verdadera, es decir, por demostrar su etiología lesional al interior del cuerpo. Desde sus primeros intentos de localización en la médula espinal, pasando luego al empleo de la noción de "lesión dinámica" en el córtex, por la idea de "diátesis histérica", y hasta el problema de las parálisis histero-traumáticas que le permite dar un paso más hacia la desfeminización de la histeria (Charcot, 2007/1886-1887), la escuela de la Salpêtrière mostrará una basculación involuntaria y sin entusiasmo, como llevada por la exigencias de su obstinado objeto, hacia lo que Gladis Swain (2009/1997) denomina la "psiquización" de la histeria (p. 80). 
El interés de Charcot en los casos de histeria masculina y el empleo de la hipnosis desde finales de la década de 1870, marcan el punto a partir del cual la doctrina charcotiana se ve obligada a comenzar a admitir dos supuestos antagónicos. En primer lugar, lo que Paul Bercherie (1988) denomina "paradoja objetiva" (p. 95), es decir, la contundente afirmación de Charcot en relación a las parálisis histéricas, según la cual éstas eran "parálisis por imaginación" y no "parálisis imaginarias", para aclarar que esas impotencias motrices son tan reales como las que dependen de una lesión orgánica y no una mera simulación (citado en: Bercherie, 1988, p. 95). En segundo lugar, la doctrina se ve orillada a admitir que, a pesar de la realidad y de la objetividad de los síntomas, la causa de la histeria se desmaterializa cada vez más a medida que se la busca en todas partes dentro del cuerpo, escollo que tiende a llevar al límite mismo de sus posibilidades explicativas y experimentales a la anatomía patológica. De ahí que el nombre de Charcot sea mayormente importante para nosotros sobre todo por el trabajo que, en negativo y au contraire, realizó como condición para el advenimiento de la llamada "histeria psicoanalítica", de la "histeria psíquica". Por ello, Swain (2009/1994) afirma que "la neurología descorporeizó la histeria [...] sacando a la luz la anatomía imaginaria que rige sus manifestaciones (p. 209), y por su lado, Bercherie (1988) nos dice que “ese pasaje por el absurdo permitió por sí solo levantar la hipoteca $<$ nerviosa>, y que en consecuencia el descubrimiento del inconsciente dependió histórica y epistemológicamente del progreso de la patología médica" (p. 70).

El "absurdo" al que arriba la escuela de la Salpêtrière se leerá como un fallo irrevocable, pero su valor estriba en que, si bien muestra el carácter inmaterialmente orgánico de la causa de la histeria, revela, por otro lado y sin proponérselo, la materialidad relacional que incita los fenómenos de la enfermedad. Esa materialidad relacional es política en el sentido foucaultiano (Foucault, 2001/1976) del término, pues implica una relación de fuerzas, pero es también inconsciente pues se desarrolla sin la participación deliberada de los sujetos que se ponen en relación material. Así también, y no menos importante, 
como lo mostrará Freud unos años después, esa relación es eminentemente sexual ${ }^{3}$.

El médico Hippolyte Bernheim, principal rival de Charcot en la universidad de Nancy, se quejaba de que el llamado "gran ataque histérico" no era otra cosa que una invención de la propia Salpêtrière, es decir, un producto de las condiciones del hospital determinadas por el tipo de relaciones entre pacientes, médicos y el propio Charcot. El director de la escuela de Nancy afirmaba nunca haber visto uno de esos ataques fuera de la Salpêtrière, y explicaba esto planteando que la llamada "sugestiblidad" no era un rasgo patológico característico de la histeria, como lo afirmaba Charcot, sino que era la condición misma para que, en ciertas condiciones, una persona pudiera manifestar los síntomas de histeria (Ellenberger, 1976/1970). Así entonces, por efecto de la sugestibilidad y por las condiciones del propio hospital, se habría creado artificialmente algo tal como el gran ataque histérico, el cual no era entonces la cristalización última de la enfermedad real, sino el producto manufacturado por Charcot en su fábrica hospitalaria.

Para nosotros esto es de la mayor relevancia, pues lo que se muestra a través de la crítica de Bernheim no es tanto la irrealidad del fenómeno histérico, sino más bien su dependencia respecto de ciertas condiciones que pudiéramos calificar de "relacionales", es decir, su dependencia respecto de ciertas formas de relación establecidas entre la o el histérico y una instancia de poder y saber que, en el caso del hospital de la Salpêtrière, ponía en juego todo un aparato extremadamente prolijo de observación para ofrecer a la mirada de los médicos y de un público amplio la sintomatología histérica.

El filósofo Georges Didi-Huberman (2007/1982) muestra cómo es que el "espectáculo" (p. 11) del cuerpo desposeído de sí mismo, el cuerpo convulsivo de la histérica, dependía inexorablemente de las condiciones específicas del hospital. La Salpêtrière funcionaba como una enorme maquinaria de observación para extraer y hacer emerger

3 No aludimos aquí al sentido matemático en que la palabra "relación" es usada por Jacques Lacan cuando afirma que "no hay relación sexual". 
desde los cuerpos el fenómeno histérico, imponiéndoles una serie de controles, exigencias, conminaciones sutiles o duras, para transformarlo en imagen, en espectáculo, en fotografía. El papel de la mirada en la constitución de ese fenómeno es mucho más que meramente científico, no es solamente una mirada aséptica que se dirige desde afuera hacia el objeto en naturaleza propia; esa mirada es fundamental y funge como la condición constitutiva del fenómeno histérico que, en tanto que se muestra como un espectáculo, está siempre dirigido a la mirada del otro, la cual retroactivamente no deja de solicitarlo y propiciarlo en el terreno de la intersubjetividad.

Se crea así un saber nuevo, el saber de la histeria; no era éste un saber derivado de los datos puros que se ofrecen tersamente a la mirada de los médicos, sino un saber producido, extraído, arrancado, propiciado en virtud de una ciencia y una tecnología que no tenía nada de neutrales. Michel Foucault (2005/1973) en su curso del Colegio de Francia titulado El poder psiquiátrico, plantea sobre lo anterior que en el contexto del escenario práctico de la psiquiatría en el siglo XIX, es decir en el asilo, las histéricas habrían sido las primeras representantes de un movimiento antipsiquiátrico. Foucault verá en la histeria menos una enfermedad que un fenómeno de lucha, a través del cual las enfermas respondían a un saber y un poder disciplinarios que, amparándose en el mero privilegio que se arrogaba la psiquiatría por ser una ciencia, reducía la terapéutica a una imposición disimétrica de fuerzas. Así entonces, para Foucault (1973) las histéricas habrían sido las "verdaderas militantes de la antipsiquiatría" (p. 302), puesto que bajo ese nombre debe entenderse todo movimiento que reintrodujera la cuestión de la verdad en la locura, que volviese a traer la problemática de la relación de los síntomas y la cura con una verdad (Vallejo, 2006).

Por ello, el psicoanálisis estaría también inscrito en esa tradición antipsiquiátrica, pues el movimiento teórico y técnico-terapéutico efectuado por Freud desde principios de la década de 1890, permitió buscar la causa de los síntomas histéricos no ya en alguna región oculta de la anatomía, sino en la narrativa histórica del pasado del sujeto, narrativa que muestra el punto de rompimiento de las asociaciones como recuerdos a consecuencia del acontecimiento traumático. 
El movimiento desde la inicial teoría traumática freudiana, pasando por su desconfianza en la veracidad fáctica del relato de la histérica y hasta el arribo a una concepción estrictamente psicoanalítica respecto de la realidad fantasmática y deseante que cristaliza el discurso del paciente, confirma que para el psicoanálisis el síntoma histérico, en su irracionalidad aparente, es sin embargo revelador de un núcleo de verdad, verdad en relación al sujeto, pero también verdad de la condición psicosocial del sujeto. Por ello la noción de "transferencia" para Freud (2004/1912; 2004/1914; 2004/1915) será esencial en la técnica y en la terapéutica psicoanalíticas, pues muestra que el medio de curación es del mismo tipo que la causa de la enfermedad: intersubjetivo. Dicha noción y su empleo técnico en la clínica permitirá a Freud -aun cuando él mismo no lo haya pretendido así- la desmitificación de la pseudonaturaleza de la enfermedad histérica y su reconducción hacia su génesis relacional, social y cultural, como producto sintomático y crítico que muestra la verdad de la humana inadaptabilidad del sujeto a un sistema deshumanizante (Dahmer, 1983/1973).

\section{Conclusión: todo síntoma es histérico por cuanto realiza una crítica}

Para el psicoanálisis la histeria representa algo más que una condición sine qua non de su propia emergencia histórica, es también, como para Michel Foucault, antes que una patología o una anormalidad, un discurso desafiante que interpela y desmiente a la ciencia y al poder dominantes. Ni las leyes de la anatomía, ni las reglas de la patología, nada de ellas funciona como cabría esperar al tratar de explicar a la histeria, ni siquiera la lesión cerebral tiene materialidad. La histeria es un desafío a cuantos se arrogan el saber y el poder, y en este sentido, en su desafío, la histeria también incita, puesto que con su reto consigue despertar al amo y empujarlo hasta, como dice Jacques Lacan, el "pie del muro de producir un saber" (citado en: Astudillo del Valle, Esteban-Arnáiz, Álvarez-Martínez, 2010, p. X).

La enseñanza lacaniana desde finales de los años sesenta, particularmente después de los acontecimientos de mayo del 68, comienza 
a delinear la especificidad de una noción de discurso a partir de la cual se materializarían cuatro formas de economía discursiva que dan fundamento al lazo social y que permiten situar la manera en que el sujeto goza en su calidad de sujeto hablante, a saber: el discurso del amo, el discurso de la universidad, el discurso del psicoanálisis y el discurso de la histeria. Para entender cabalmente el meollo del discurso histérico, habría que ponerlo en relación con los otros tres, tarea que excede por mucho las posibilidades de la comunicación presente. En su seminario correspondiente a los años 1969-1970, Lacan (2002/1975) afirma respecto de la histérica:

Ella quiere un amo (...) Quiere que el otro sea un amo, que sepa muchas cosas, pero de todas formas que no sepa las suficientes como para no creerse que ella es el premio supremo de todo su saber. Dicho de otra manera, quiere un amo sobre el que pueda reinar. Ella reina y él no gobierna (p. 137).

El matema correspondiente al discurso de la histeria coloca en relación a un sujeto que interpela a un amo en función de un deseo de saber. La función del síntoma histérico es la de una pregunta, por ello el agente es propiamente el síntoma mismo, el cual desenmascara a un amo respecto de la imposibilidad fundamental que éste tiene para responder en su estatuto ilusorio de "todo saber". El problema fundamental que plantea la pregunta histérica es el de la relación sexual, una pregunta que "se le plantea al sujeto en el plano del significante, en el plano del to be or not to be, en el plano de su ser" (Lacan, 2004/1981, p. 239). La estructura de la pregunta, como la de toda pregunta, es esencialmente simbólica, no tiene nada que ver con la forma en que la sexualidad se encarrila en el terreno de la animalidad mediante el patrimonio instintivo. Esto demuestra, como ya lo mencionábamos, que la aparente naturaleza de la enfermedad histérica es en realidad una pseudonaturaleza, pues su génesis y su dominio son simbólicos y, por lo tanto, intersubjetivos.

El discurso histérico requiere un amo, pero requiere especialmente un superior al que contraponerse y derrocar. Por ello la relación de la histérica con el amo es una relación de poder, de desafío, de estrategia. El paralelismo que Lacan (2002/1975) encuentra entre la histérica 
y la clase proletaria es, a este respecto, destacable, pues el valor sintomático del malestar del trabajador, de su alienación en el trabajo, de su deshumanización, muestra críticamente -al igual que el síntoma histérico- algo más que una mera condición atípica, anormal y extraña. Este síntoma se muestra así mismo como una crítica que permite entender que tanto la histérica como el proletariado han sido, además de explotados, despojados de su saber.

$\mathrm{Al}$ revelarse la verdad de la histeria y de la clase proletaria -cuyo saber no se encuentra ni en la propia histérica, reducida a la condición de enferma, ni en el propio proletariado, segmentado y alienado, sino fuera de ellos- también se muestra que dicha condición es inaceptable, y desde el momento en que se la contempla en lo que es en sí misma, en su faz brutal e intolerable, ya podemos comenzar a transformarla. Por ello David Pavón-Cuéllar (2014) afirma que el discurso de la histérica y el movimiento revolucionario del proletariado coinciden al formar parte del "acontecimiento político-subversivo", ya que vehiculizan la enunciación y la denunciación, la des-identificación con el significante amo, fungen como un cuestionamiento al poder, permiten la des-ideologización y la des-idealización por la irrupción de la verdad en el saber y corresponden a la insurrección y a la emancipación (p. 164).

Hemos tratado de demostrar que todo síntoma histérico es, no la manifestación representante de una lesión o etiología orgánica, ni tampoco un problema de orden estrictamente natural, sino el signo de una pregunta que no tiene respuesta, pues muestra el límite y el fallo del orden significante en el terreno de la sexualidad. La sexualidad sería el real indomable que retorna sintomáticamente como consecuencia del quiebre simbólico inevitable al que se enfrenta cada sujeto en la encrucijada de la pregunta por su sexo. La pregunta histérica muestra siempre ese fallo, muestra de forma paradigmática el impase en la relación sexual, su imposibilidad. Este problema, de acuerdo a Alain Badiou (2009/1982), es el anclaje materialista del psicoanálisis, de la misma manera que el problema de la imposibilidad de las relaciones de clase es el anclaje materialista del marxismo: “(...) si lo real del psicoanálisis es la imposibilidad de lo sexual como relación, lo real del marxismo se enuncia: 'No hay relaciones de clase'. ¿Qué significa 
esto? Puede decirse de otro modo: antagonismo" (p. 153). Lo que aquí más interesa destacar es que este materialismo de los cuerpos, pero también de las relaciones sociales, es un materialismo que no puede entenderse sino en su forma antagónica, en la lucha permanente que lo constituye y que imposibilita cualquiera verdadera "relación" en el sentido matemático de complementariedad, su absoluta inserción y resolución en el orden simbólico.

Así por ejemplo -y volviendo sobre el problema de la brujería que es, de acuerdo a lo que tratamos de demostrar, el problema del cuerpo que se rebela ante un amo en el plano del significante- Silvia Federicci (2004) propone que la persecución de las brujas desde el Renacimiento ha de entenderse como la prolongación de la lucha de clases por otros medios, y que el miedo al sabbath es al mismo tiempo el miedo a las reuniones campesinas en donde se gestaban las sublevaciones contra los señores feudales. Por ello, Federicci no deja de afirmar que la caza extendida de brujas en la Europa de los siglos XVI al XVIII fue una condición necesaria, paralela a la acumulación de la riqueza originaria para el tránsito del feudalismo al capitalismo. El cuerpo de la bruja marcado por el diablo es también un cuerpo que se resistió, tanto como pudo, a entrar en los controles sexuales de la biopolítica, entendida como gestión de la producción y reproducción de cuerpos como mano de obra industrial y militar requerida en los albores del capitalismo y en la formación de los Estados-nación modernos.

Es lícito afirmar que todo síntoma tiene un estatuto histérico por cuanto revela una verdad a manera de crítica, de interpelación, de subversión en contra de una estructura significante de saber y de poder dominante. La parálisis, la convulsión, el dolor histérico, etc., en toda su irracionalidad revelan una verdad, pues son irracionales sólo desde el punto de vista de una aparente racionalidad que se pretende esférica que es la de la ciencia médica y psiquiátrica. Dialécticamente, la irracionalidad del síntoma histérico se habrá de tornar perfectamente racional retroactivamente, a posteriori, si es que se pone en relación con una verdadera ciencia crítica como el psicoanálisis o el materialismo histórico (Braunstein, 2006/1975), que no pretenda subsumirlo en una lógica sistemática devoradora y voraz. Por ello el valor del síntoma es el de revelar no únicamente la verdad de un sujeto 
sino la verdad estructural de un sistema en toda su irracionalidad totalitaria y totalizante. El síntoma histérico, irracional a los ojos del psiquiatra, revela (y rebela) su racionalidad al denunciar la irracionalidad obscena de la racionalización médica del malestar humano. Para captar dialécticamente esta denuncia sintomática en su pleno valor de verdad, no habría que colocarla ni leerla en el nivel de su formulación consciente sino inconsciente, no en el plano del conocimiento sino del saber no sabido, no en el enunciado sino en la enunciación.

Querría entonces finalizar este recorrido, en donde se ha intentado mostrar cómo es que las manifestaciones corporales y anímicas de los fenómenos histéricos, en diferentes momentos históricos y en diferentes contextos sociales, no pueden comprenderse sin ser enmarcados en un cierto número de relaciones de orden discursivo y político. No quiero afirmar, como se viene haciendo desde hace cierto tiempo desde la perspectiva de un historicismo rampante e ingenuo, que las manifestaciones de la histeria son nada más que el producto secundario, los efectos del ejercicio de dichos mecanismos de saber y poder sobre el cuerpo ${ }^{4}$.

Se ha pretendido mostrar que la histeria no deja de demarcar una y otra vez el límite mismo del ejercicio de dichos mecanismos. Y que

4 Como de hecho parece sugerirlo Mauro Vallejo (2006) siguiendo a Foucault: “¿Qué puede ser la histeria absuelta de la dispersión de mecanismos que la nombran como patología, carente de todas las medidas técnicas y prescripciones discursivas que la colocan al lado de otros desarreglos de la salud o el deseo, distanciada de las figuras que la recortan del trasfondo oscuro de otros hechos, carente de su médico, de su psiquiatra, de su hipnotizador o de su psicoanalista? Sin todo ello, sin todos esos indicios del cuidado que se le dedican, la histeria no es nada" (p. 129). Es claro que Vallejo no pretende negar la existencia histórica de la histeria, solamente pretende mostrar la dependencia de esa existencia respecto de los discursos y los mecanismos que la cercan y la nombran. Sin embargo, al afirmar que sin todos esos discursos y mecanismos, la histeria "no es nada", me parece que niega lo que de hecho sí "habrá de ser" la histeria en su materialidad más allá de esos mecanismos. La histeria, una vez analizada mediante las herramientas de una ciencia crítica, habrá de ser y habrá de mostrarse en su verdad propia como aquello que se resiste, por su propio exceso de vitalidad, a ser subsumido plenamente al interior del sistema simbólico de la cultura. 
el cuerpo sobre el que recaen los efectos de las redes de poder y de saber no es un mero producto pasivo de aquellos, sino que en su propia inmanencia ese cuerpo manifiesta una vitalidad refractaria, una resistencia indócil, una obstinación, una intransigencia que cuestiona, que socava, que derriba una y otra vez aquel aparato complejo que se pone en marcha para cercar y someter a los cuerpos, sobre todo el cuerpo de la mujer, pero también el del homosexual, el del delincuente, el del loco, el del obrero, etc. Así, el discurso lingüístico, pero también el discurso corporal de la histeria, se establece siempre como una oposición, como la contraparte en una lucha cuyo opuesto es el discurso oficial de una teología, de una moral, de una economía, de una ciencia médica, etc. El síntoma histérico es un discurso impugnador, contestatario, subversivo, revolucionario, que muestra, como lo ha enunciado Jacques Lacan, que ningún sistema simbólico puede devorar en su interior la totalidad de lo real, en este caso de lo real corporal, pues éste siempre se resiste, siempre retorna. El discurso histérico, en todo lo que tiene de heteróclito en sí mismo, se hace valer siempre como una crítica a algún saber y a algún poder que pretenda tener un pleno dominio sobre los cuerpos.

\section{Referencias}

Agamben, G. (2006). Homo Sacer. El poder soberano y la nuda vida. Valencia, España: Pre-textos.

Arendt, H. (2010/1958). La condición humana. Buenos Aires, Argentina: Paidós.

Astudillo del Valle, H., Esteban-Arnáiz, R., Álvarez-Martínez, J. M. (2010). Presentación. La histeria antes de Freud. Madrid, España: Edición de Alienistas del Pisuerga.

Badiou, A. (2009/1982). Teoría del sujeto. Buenos Aires, Argentina: Prometeo.

Bercherie, P. (1988). Génesis de los conceptos freudianos. Buenos Aires, Argentina: Paidós.

Braunstein, N. (2006/1975). ¿Qué entienden los psicólogos por psicología? En: Braunstein, N., Parternac, M., Benedito, G., Saal, F. Psicología: Ideología y ciencia. México: Siglo Veintiuno Editores.

Charcot, J. M. (1981/1882). Descripción del gran ataque histérico. En: Revista de la Asociación española de Neuropsiquiatría, 2(1), 121-126. Dispo- 
nible en: http://www.revistaaen.es/index.php/aen/article/view/ $14605 / 14484$.

Charcot, J. M. (2007/1886-1887). Parálisis histero-traumática masculina. En: Aldo Conti, N., Stagnaro, J.C. (Comps.). Historia de la ansiedad. Buenos Aires, Argentina: Editorial Polemos.

Dahmer, H. (1983/1973). Libido y sociedad. Estudios sobre Freud y la izquierda freudiana. México: Siglo Veintiuno Editores.

De Certeau, M. (2012/1970). La posesión de Loudun. México: Universidad Iberoamericana.

Delumeau, J. (2012/1978). El miedo en Occidente. México: Taurus.

Didi-Huberman, G. (2007/1982). La invención de la histeria. Charcot y la iconografía fotográfica de la Salpêtrière. Madrid, España: Cátedra.

Ellenberger, H. F. (1976/1970). El descubrimiento del inconsciente. Historia y evolución de la psiquiatría dinámica. Madrid, España: Gredos.

Federicci, S. (2004). Calibán y la bruja. Mujeres, cuerpo y acumulación originaria. Madrid, España: Traficantes de sueños.

Foucault, M. (2001/1976). Historia de la sexualidad. 1. La voluntad de saber. México: Siglo Veintiuno Editores.

Foucault, M. (2005/1973). El poder psiquiátrico. Buenos Aires, Argentina: Fondo de Cultura Económica.

Foucault, M. (2006/1974). Los anormales. México: Fondo de Cultura Económica.

Freud, S. (2004/1912). Sobre la dinámica de la transferencia. En J. Strachey (Ed.) y J.L: Etcheverry y L. Wolfson (Trads.). Obras completas (Vol. XII, pp. 93-105). Buenos Aires, Argentina: Amorrortu.

Freud, S. (2004/1914). Recordar, repetir y reelaborar. En J. Strachey (Ed.) y J.L: Etcheverry y L. Wolfson (Trads.). Obras completas (Vol. XII, pp. 145157). Buenos Aires, Argentina: Amorrortu.

Freud, S. (2004/1915). Puntualizaciones sobre el amor de transferencia. En J. Strachey (Ed.) y J.L: Etcheverry y L. Wolfson (Trads.). Obras completas (Vol. XII, pp. 159-174). Buenos Aires, Argentina: Amorrortu.

Gauchet, M., Swain, G. (2000/1997). El verdadero Charcot. Los caminos imprevistos del inconsciente. Buenos Aires, Argentina: Ediciones Nueva Visión.

Lacan, J. (2004/1981). El seminario de Jacques Lacan, libro 3: Las psicosis (19551956). Buenos Aires, Argentina: Paidós.

Lacan, J. (2002/1975). El seminario de Jacques Lacan, libro 17: El reverso del psicoanálisis (1969-1970). Buenos Aires, Argentina: Paidós.

Laqueur, T. (1994/1990). La construcción del sexo. Cuerpo y género desde los griegos hasta Freud. Madrid, España: Cátedra.

Maleval, J.-C. (1994). Cómo desembarazarse de la histeria o la histeria en el siglo XX. En: Revista de la Asociación Española de Neuropsiquiatría, 49(14), 
269-290. Disponible en: http://www.revistaaen.es/index.php/aen/article/view/15372/15233.

Nucamendi, G., Guillén, G. y Sánchez, M. (2013). Fibromialgia. En: Vigilancia Epidemiológica Semana, 29, 1-28. Disponible en: https://www.gob.mx/ cms/uploads/attachment/file/13762/2013_29.pdf.

Pavón-Cuéllar, D. (2014). Elementos políticos de marxismo lacaniano. México: Paradiso Editores.

Pedraza, P. (2014). Brujas, sapos y aquelarres. Madrid, España: Valdemar. Platón. (2000/360 a.C.). Timeo. En: Diálogos. México: Editorial Porrúa.

Pomeroy, S. B. (1999/1987). Diosas, rameras, esposas y esclavas. Madrid, España: Akal Ediciones.

Rausky, F. (1977). Mesmer: el periodo parisino. En: http://www.elseminario. com.ar/biblioteca/rausky_mesmer.htm.

Simon, B. (1984/1978). Razón y locura en la antigua Grecia. Madrid, España: Akal Ediciones.

Swain, G. (2009/1994). El alma, la mujer, el sexo y el cuerpo. En: Swain, G. Diálogo con el insensato. Madrid, España: Asociación Española de Neuropsiquiatría.

Vallejo, M. (2006). Incidencias en el psicoanálisis de la obra de Michel Foucault. Buenos Aires, Argentina: Letra Viva. 